unlikely that chaining played an important role in the performance of the other two pigeons, since their responding in $\mathrm{S} 2$ decreased quite rapidly to a very low level. Another possibility is that both the excitatory properties of $\mathrm{S} 2$ and the reduction in responding in its presence were generated directly by the signal for reinforcement. Indeed, the fact that reinforcement frequency was held constant at the baseline level in Component 2 may, in itself, have been sufficient to maintain the excitatory properties of $\mathbf{S 2}$ that were established under baseline training (cf. Catania, 1961). Insofar as introduction of the signal increased the predictability of reinforcement, the favorability of this component was presumably increased. Responding in the presence of S2, which the signal made redundant with respect to obtaining reinforcement, may have been simply omitted or replaced with an alternative behavior without being actively inhibited. In terms of this analysis, the reinforcement signal could be thought of as controlling a low rate of responding by making it redundant. Such control would be consistent with the large increase in responding in the presence of $\mathrm{S} 2$ when the signal was removed during the generalization test. In short, the results appear to be most readily handled in terms of excitatory control exercised by the reinforcement properties of Component 2.

The results provide evidence that the signaled reinforcement procedure is one in which a reduction in response rate alone is not sufficient for the production of inhibitory control on a stimulus dimension. Since contrast effects have been found with this procedure, both in previous studies and in the present one, these results also weaken the case for a correlation between the occurrence of behavioral contrast and the development of inhibitory stimulus control. The signaled reinforcement procedure itself appears to have interesting properties which could be valuable in the analysis of the derterminants of stimulus control.

\section{REFERENCES}

BALDOCK, M. D. Positive behavioral contrast: Response suppression and the signalling of reinforcement. Unpublished Master's thesis, University of Canterbury, 1970.

BROWNSTEIN, A. J., \& NEWSOM, C. Behavioral contrast in multiple schedules with equal reinforcement rates. Psychonomic Science, 1970, 18, 25-26.

CAT ANIA, A. C. Behavioral contrast in a multiple and concurrent schedule of reinforcement. Journal of the Experimental Analysis of Behavior, 1961. 4, 335-342.

HEARST, E., BESLEY, S., \& FARTHING, G. W. Inhibition and the stimulus control of operant behavior. Journal of the
Experimental Analysis of Behavior, 1970 $14,373-409$

REYNOLDS, G. S. Positive behavioral contrast: Development within sessions. Psychonomic Science, 1968, 10, 321-322.

TERRACE, H. S. Stimulus control. In W. K. Honig (Ed.), Operant behavior: Areas of research and application. New York: Appleton-Century-Crofts, 1966 . Pp. 271-344.
WEISMAN, R. G. Some determinants of inhibitory stimulus control. Journal of the Experimental Analysis of Behavior, $1969,12,443-450$.

WEISMAN, R. G. Factors influencing inhibitory stimulus control: Differential reinforcement of other behavior during discrimination training. Joumal of the Experimental Analysis of Behavior, 1970. 14, 87-91.

\title{
Schedule-induced polydipsia with nutritive and nonnutritive reinforcers
}

\author{
EARL X. FREED \\ Alcohol Research Laboratory, V.A. Hospital, Lyons, N.J. 07939
}

Eighteen Charles River (cd) male rats were conditioned to drink water polydipsically by the delivery of food pellets on FFI $45 \mathrm{sec}$, and then, varying percentages of sweetened nonnutritive pellets were substituted for the nutritive pellets. The mean volume of water ingested decreased with decreased nutritive content of the pellets, suggesting a relationship between schedule-induced polydipsia in the rat and the nutritive content of the reinforcer.

Intermittent delivery of a food substance to a food-deprived rat is accepted as a necessary condition for the development and maintenance of schedule-induced polydipsia. Unresolved, however, is the issue of the relationship between the magnitude of the reinforcement and the amount of water ingested. Keehn (1970) suggested that a 21-pellet reinforcer induced longer drinks, while there was only a weak relationship between number of pellets per reinforcement and drink size for $1,3,6$, and 9 pellets. Falk (1967) had earlier reported that smaller portions per reinforcement produced increased water intake per session. On the other hand, in a partial replication, Hawkins, Everett, Githens, \& Schrot (1970) found that increasing the portion size enhanced the level of drinking, reinterpreting Falk's (1967) results to indicate the same thing if one controlled for session length and did not evaluate solely the total volume consumed per session. Rosenblith (1970) also reported a greater amount of water drinking per interpellet interval with $250 \cdot \mathrm{mg}$ food pellets than with 45-mg pellets.

A summary (Falk, 1969) of the issues involved in parameter control in such research cited the animal's motivation, the motivational or reinforcing properties of the food, interpellet time, etc. To these must be added the above control on session length, as well as caloric value, as determiners of the reinforcing properties of food. Although Falk (1967) concluded that "caloric value per reinforcement, when compared across diets [was not] a predictor of drinking" of water, other studies (Freed, Carpenter, \& Hymowitz, 1970; Freed \& Lester, 1970) have suggested that, if the fluid is ethanol, its caloric value may be a prime factor in both its polydipsic consumption and in its resistance to extinction.

The present study attempted to elucidate further the relationship between polydipsia and its food determinant through the substitution of nonnutritive pellets, equal in size and weight to $45-\mathrm{mg}$ Noyes food pellets but devoid of caloric value. Thus, while the number of reinforcements (or meals) and session length were held constant, the motivational property of the reinforcer was varied. By delivering the pellets on a free fixed-interval (FFI) schedule, barpress behavior, which presumably would reflect qualitative changes in food pellets, was eliminated as a possible confounding factor in Ss' drinking behavior. 
Table 1

Data on Fluid Intake During Phases of the Experimental Program

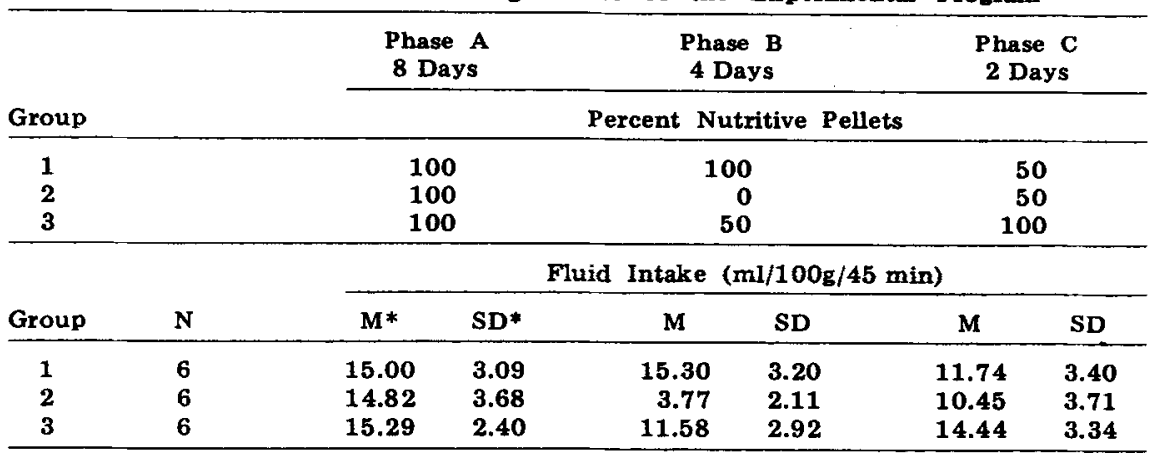

* Data reported for Days $5-8$.

\section{SUBJECTS AND APPARATUS}

The Ss were 18 Charles River (cd) male rats, 45-50 days old and weighing between 110 and $184 \mathrm{~g}$ at the start of the experiment. Ss were housed individually with water and Purina Lab Chow ad lib. Apparatus consisted of a sound-attenuated Grason-Stadler operant chamber, a 45-mg pellet dispenser, solid-state programming equipment, and a stainless steel drinking spout externally attached to a calibrated cylinder of tap water, accessible through a slot cut in the chamber wall. Licks were recorded by a counter and a cumulative recorder. PROCEDURE

Following 8-11 days of ad lib feeding, Ss were placed on a limited feeding regimen for 7 days and reduced to $75 \%$ of their respective free-feeding weights. Ss were divided into three experimental groups of equated mean weight. The experimental design is shown in the upper portions of Table 1 . During the study, Ss were fed $2 \mathrm{~h}$ after each day's experimental session.

A preliminary day in the operant chamber acquainted $S$ with the FFI schedule. S received 30 Noyes $45-\mathrm{mg}$ Laboratory Animal Food pellets on FFI $10.5 \mathrm{sec}$, then 30 on FFI $20 \mathrm{sec}$, and finally, 40 on FFI 45 sec. Eight daily 45 min sessions ensued, in each of which $S$ received 60 pellets on FFI 45 .

During the next two phases of the study, the treatment groups received varying percentages of nutritive reinforcers by the substitution of sweetened 45-mg Noyes nonnutritive pellets for food pellets. On the 50\% nutritive schedule, equal proportions of nutritive and nonnutritive pellets were mixed in the pellet-feeder reservoir and were delivered randomly to $\mathbf{S}$.

\section{RESULTS}

Data on fluid intake are reported at the bottom of Table 1 .

Phase $A$ analysis of variance failed to reveal a significant difference between the groups' drinking behavior, indicating that the three experimental groups were equated during pretreatment in terms of their drinking. There was, however, a significant $(p<.001)$ days effect due to the development of drinking in time, specifically during the first 4 days. Later, water consumption per session stabilized.

In an analysis of variance of Phase $B$, treatment $(\mathrm{F}=35.33, \mathrm{df}=2 / 15$, $p<.01)$ and days $(F=7.78$, $\mathrm{df}=3 / 45, \quad \mathrm{p}<.01$ ) effects were significant. $\mathrm{F}$ and $\mathrm{t}$ tests comparing Group 1's Phases A and B drinking were not significant. Reductions in volumes of water consumed, relative to percent of nutritive pellets, were seen in Groups 2 and 3.

This was confirmed in Phase $C$, where Group 3's M water consumption on $100 \%$ nutritive pellets did not differ significantly from its own $M$ or Group 1's $M$ in Phase A on $100 \%$. Although analysis of variance of Phase $C$ drinking did not yield a significant treatment effect, a $t$ test comparing the combined scores of Groups 1 and 2 (on $50 \%$ nutritive pellets) and Group $3(100 \%)$ was significant at $p<.01$, with the $\mathrm{Ss}$ receiving fewer nutritive pellets drinking less.

\section{DISCUSSION}

Drinking rates were greatest with $100 \%$ nutritive pellets. There appeared to be a relationship between the nutritive content of the reinforcement and the amount of water ingested. By implication, this relationship also holds for magnitude of reinforcement and amount of polydipsia if one regards "magnitude" as amount of nutritive value delivered per session. Of course, another interpretation is that Ss receiving $50 \%$ nutritive pellets randomly on FFI 45 sec were, in effect, on a food pellet schedule averaging VI $90 \mathrm{sec}$ and that the increased interfood pellet interval was responsible for their reduced drinking. However, Freed and Hymowitz (unpublished research, 1971) showed an increase in drinking per session with increased interpellet intervals, and Falk (1966) showed that drinking increased as FI values increased, finally falling at FI $300 \mathrm{sec}$.

Observation of $\mathrm{Ss}$ on the $50 \%$ nutritive schedule indicated that drinking bursts generally followed each reinforcement but were seemingly not as long (or as efficient) as when all pellets were food. Generally, all the pellets delivered were eaten.

There is no doubt that Ss could discriminate between the two types of pellets after eating them. In a pilot study employing a simultaneous paradigm, food-deprived rats were given both kinds of pellets in their home cages. Initially, Ss ate only the food pellets, but, as deprivation continued for a few days, all pellets were eaten. The $5 \%$ saccharin content of the nonnutritive pellets is a distinctive orosensory cue. Perhaps the nonnutritive pellets were ingested during the experimental sessions because they had acquired a secondary reinforcement value.

Results argue against frustrative nonreward as an explanation of schedule-induced polydipsia, for this theory would predict that Ss switched from $100 \%$ to $50 \%$ nutritive reinforcement should drink more water, and, in fact, they drank less. In the present study, the more aversive reinforcement schedule resulted in reduced polydipsia.

\section{REFERENCES}

FALK, J. L. Schedule-induced polydipsia as a function of fixed interval length. Journal of the Experimental Analysis of Behavior, 1966, 9, 37-39.

FALK, J. L. Control of schedule-induced polydipsia: Type, size and spacing of meals. Journal of the Experimental Analysis of Behavior, 1967, 10, 199-206.

FALK, J. L, Conditions producing psychogenic polydipsia in animals. Annals of the New York Academy of Sciences, $1969,157,569-593$.

FREED, E. X., CARPENTER, J. L., \& HYMOWITZ, N. Acquisition and extinction of schedule-induced polydipsic consumption of alcohol and water. Psychological Reports, 1970, 26,
915-922.

FREED, L. X., \& LESTER, D. Schedule-induced consumption of ethanol: Calories or chemotherapy? Physiology \& Behavior, $1970,5,555-560$. HAWKINS, T. D., EVERETT. P. B. GITHENS, S. H., \& SCHROT, J. R. Adjunctive drinking: A functional analysis of water and alcohol ingestion. In $\Delta c h e d u l e-i n d u c e d \quad a n d$ schedule-dependent phenomena. Vol. 1. Toronto: Addiction Research Foundation, 1970. Pp. 227-286.

KEEHN, J. D. Beyond the law of effect. In $S c h e d u l e-i n d u c e d$ and schedule-dependent phenomena. Vol. 1. Toronto: Addiction Research Foundation, 1970. Pp. 137-186.

ROSENBLITH, J. Polydipsia induced in the rat by a second-order schedule. Journal of the Experimental Analysis of Behavior, $1970,14,139-144$. 